\title{
Government spending under alternative yield risk management schemes in Finland
}

\author{
${ }^{1}$ Petri Liesivaara, ${ }^{2}$ Miranda Meuwissen, ${ }^{1}$ Sami Myyrä \\ ${ }^{1}$ Natural Resources Institute Finland (Luke) \\ ${ }^{2}$ Department of Social Sciences, Business Economics, Wageningen University \\ e-mail: petri.liesivaara@gmail.com
}

\begin{abstract}
The need for efficient risk management has increased in agriculture, as farmers are facing greater risks, for instance, due to climate change, price liberalisation and new plant diseases. The development of yield insurances is ongoing in many EU member countries. In Finland, the northernmost EU country, a government-financed crop damage compensation (CDC) scheme has been abolished. In this study, we analysed how the government's expenditure would change due to the policy shift and provide insight into the tails of the loss distribution of a crop insurance scheme based on individual farm yields. According to a stochastic simulation model, the mean expenditures for the government as well as the variability in expenditure between years are expected to be lower as a result of the policy shift. The results obtained support the government's decision to terminate the CDC scheme.
\end{abstract}

Keywords: government expenditures, crop insurance, stochastic simulation

\section{Introduction}

Adverse weather events can lead to considerable economic losses for farmers. These losses are often compensated by governments. In Europe, the emphasis is moving from government-run programmes and disaster relief to insurances based on public-private partnership (PPP) (Meuwissen et al. 2013). In PPP, governments subsidise farmers buying yield insurance from private insurance companies. The European Union (EU) is also promoting the use of PPP in the Common Agricultural Policy (CAP). The CAP was reformed in 2015, and member states will be able to use premium subsidies for crop insurances based on PPP as part of rural development (EU 2013).

The decision made at the EU level to promote yield insurances through rural development opens new possibilities for EU member countries to strengthen risk management in agriculture (Meuwissen et al. 2013). The need for efficient risk management has increased in agriculture, as farmers are facing greater risks, for instance, due to climate change, price liberalisation and new plant diseases. The development of yield insurances is ongoing in many EU member countries. Although private and public-private crop insurance schemes already exist in various EU countries (Smith and Glauber 2012), numerous obstacles may slow down the implementation of new risk management schemes. For example, a lack of viable infrastructure (such as trained loss adjusters and product delivery systems) and sufficient data may cause major obstacles to the development of crop insurance schemes, even in developed countries (Smith and Glauber 2012).

Finland is an example of a developed EU member country renewing its rules for crop damage compensation. As Finland is situated at the northern limit of agriculture, the harsh climate increases yield variability. In Finland, a government-run crop damage compensation (CDC) scheme was already put into use in 1976. The CDC scheme was fully financed by the government, i.e. participation was free of charge for the farmers. However, the scheme was widely criticized, because it did not provide cover for all farmers. Under the CDC scheme, compensation payments were based on area reference yields, but loss inspection was carried out at the farm level, and the scheme did not therefore provide cover for farms operating at high yield levels (Myyrä and Pietola 2011). The CDC scheme was abolished in 2015, not only due to policy shifts to PPP at the EU level, but also because of problems related to the above-mentioned area reference yields and moral hazard (Myyrä and Pietola 2011, Myyrä and Jauhiainen 2012).

The Finnish government did not provide crop insurance premium subsidies in 2016-2017, as it wanted to give room for innovative private sector solutions. However, the situation may change rapidly if the private sector is not willing to introduce crop insurance products for farmers or if the new insurance products do not attract much attention.

Finnish insurance companies are well aware of the large liabilities related to crop insurances, because they have experienced large losses within the last few years in another natural resources-related industry. Indemnity payments to forest owners in Finland amounted to 32 million Euros as a result of a storm in 2011, which caused severe financial losses for Finnish insurance companies (MT 2013). Such financial losses suggest that sound insurance practices have not been used in forest insurance premium calculations. 
The Finnish government has benefitted from the abolition of the CDC scheme, as it no longer needs to cover all expenditures from the risk management scheme. However, it also raises questions, among others, with regard to the type of crop insurance that is needed (e.g. premium subsidies versus some type of reinsurance agreement, and public-private versus a fully private scheme), where to set retention levels for the farm sector and to what extent the overall risk exposure will change due to the switch to a farm-based scheme.

Literature is available on the risk exposure of various sectors, such as horticulture in the Netherlands (van Asseldonk et al. 2001) and the pig production sector in Finland (Niemi et al. 2008), Belgium (Mintiens et al. 2003) and the Netherlands (Mangen et al. 2002). There have also been publications on cost-sharing agreements between public and private sectors (see e.g. Meuwissen et al. [2003] for swine epidemics). Although the switch to a fully private or public-private scheme appears beneficial for multiple reasons, including incentives for good farming practices (Meuwissen et al. 2001), the uncertainty for governments and private insurers may delay the actual implementation of the new system. Subsidised risk management tools will also lead to a higher market income risk for farmers (Goodwin and Vado 2007).

Governments increasingly take the role of a risk-sharing partner in PPP solutions for risk management. In this context, the objective of this study was to estimate how government expenditure would change in Finland due to the policy shift from a crop damage compensation system fully financed by the government to an insurance scheme based on PPP. Thus, fair premiums and the reserve loadings of the farm insurance scheme were calculated. We developed a stochastic simulation model to study the risk exposure of crop insurance based on individual farm yields in Finland. FADN (The Farm Accountancy Data Network ) data were used as an input. In addition, historical indemnities of the CDC scheme were used to define the possible losses of the government-run scheme.

This paper contributes to current policy debates on PPP in crop insurances. In addition, it provides insight for governments, farmers and insurance companies into the future risk exposure and expenditures under a farmbased insurance scheme. In section 2, the CDC scheme, the farm-based insurance scheme based on FADN data and the research methods are described. In section 3 , the results from the stochastic simulation model are presented and compared with the historical indemnities of the CDC scheme. Section 4 provides discussion and conclusions.

\section{Data and estimation method}

In this section, the design of the CDC scheme and the farm-based insurance are described and discussed. In the analysis, we combine two different datasets: CDC and FADN data. In this section, both datasets are introduced. The stochastic simulation model is described in the final part of this section.

\section{Crop damage compensation scheme design and data}

The Finnish CDC scheme was fully financed by the government, which means that all farmers were automatically eligible for compensation if they experience crop loss under the condition that they followed the required guidelines for good farming practices within the EU. All the major field crops were included in the scheme. However, some high-value crops, such as strawberries, were not included.

Farmers could collect CDC payments if the overall output of all crops on their farm fell below $70 \%$ of the area reference yields. Thus, even if farmers experienced total loss on a specific field, they were not eligible for compensation if the losses for the entire farm did not exceed the $30 \%$ deductible. When the farmer applied for compensation, crop losses were inspected at the farm level. The monetary compensation was a product of the quantity lost, net of the deductible, and the average producer price. The losses had to be verified on the farm before the harvest. A fixed fee was incurred to the farmer for the inspection.

The area reference yield was calculated from average yields for the previous five years in that area. Reference prices, which were the average prices of a particular year, were used as a basis for calculating the compensation payment. The system was restricted to an annual aggregate budget constraint of 3.4 million Euros. If the losses exceeded this amount and the overall compensation would exceed the budget constraint, the budget allocated to the scheme could be increased. The level of farmer-specific compensation could also be reduced to meet the budget constraint. 
CDC data were provided by the Information Centre of the Ministry of Agriculture and Forestry of Finland (TIKE), and consisted of payments per farm and the number of hectares lost from 1995 to 2012. The main cereal crops cultivated in Finland, i.e. barley, oats, winter and spring wheat and rye, were selected for this study. In 2012, the area cultivated with these crops represented $49 \%$ of the overall utilized agricultural area in Finland. On average, these crops account for $75 \%$ of the overall hectares lost in the CDC scheme.

\section{Farm-based insurance scheme design and data}

The Farm Accountancy Data Network (FADN), a cross-sectional dataset, was used for analysis of the farm-based insurance scheme based on individual yield data. The FADN is an official European Union dataset that includes detailed information on farm-specific accounts. The dataset also includes crop-specific production and cultivated hectares. The farm-specific hectare yields of winter and spring wheat, rye, oats and barley were used to calculate the average indemnity payments and fair premiums of the farm yield insurance. Our FADN dataset consisted of farm yield data for 1998-2011.

The simulated insurance contract was based on individual farm yields. This structure is also promoted by the EU (EU 2013). Total indemnities I for crop $c$ in year $t$ of the yield insurance scheme were modelled as follows:

$$
\mathrm{I}_{\mathrm{ct}}\left(\delta_{\mathrm{ct}}\right)=\sum_{\mathrm{m}=1}^{\mathrm{n}} \mathrm{p}_{\mathrm{ct}} \max \left[0,\left(\delta_{\mathrm{ct}} \overline{\mathrm{y}}_{\mathrm{ctm}}-\mathrm{y}_{\mathrm{ctm}}\right)\right]
$$

where $\delta$ is the cover of the insurance, $p$ is the price used for indemnity calculation, $\bar{y}$ is the average yield and $y$ is the actual yield realized on the farm $m$. The cover of the simulated insurance scheme was set to $70 \%$. The rules for subsidized crop insurance follow the World Trade Organization (WTO) agreements (WTO 1994), where the limit of the deductible for subsidised crop insurance has to be at least $30 \%$. Average producer prices applied in the CDC scheme were used for indemnity calculations. Average farm yields were calculated as an Olympic average, i.e. the average yield of the five previous years minus the highest and lowest values. Because FADN data for this study were only available from 1998 onwards (while the CDC started in 1995), reference yields in the CDC scheme were applied in calculating the average yield in 1998-2002. This was done to expand the available dataset. FADN farm yields were compared with reference yields used in the CDC scheme, which provides farm-specific weights $W$ for each individual farm $m$ for each crop $c$ :

$$
W_{c m}=\frac{\sum_{t=1}^{t} y_{c t m}}{\sum_{t=1}^{t} r_{c t}}
$$

where $r$ is the CDC area reference yield for crop $c$ in year $t$. These farm-specific weights $W$ were multiplied by the area reference yield for 1995-1997 in the CDC scheme. Derived weighted farm-specific reference yields were used to proxy 1995-1997 average farm yields.

Barley is the most commonly cultivated crop in terms of the average number of farms in the dataset, and also accounts for the highest average cultivated area per year on FADN farms (Table 1). The average yield of cereal crops on FADN farms is highest for winter wheat and lowest for rye.

Table 1. Descriptive statistics on the FADN dataset

\begin{tabular}{llll}
\hline & $\begin{array}{l}\text { Average cultivated } \\
\text { hectares per farm }\end{array}$ & $\begin{array}{l}\text { Average number of farms in } \\
\text { the dataset }\end{array}$ & $\begin{array}{l}\text { Average yield 1998-2011 } \mathrm{kg} \mathrm{ha}^{-1} \\
\text { (SD) }\end{array}$ \\
\hline Barley & 20.0 & 512 & $3,283(331)$ \\
Oats & 12.3 & 482 & $3,212(309)$ \\
Winter wheat & 11.4 & 61 & $3,697(426)$ \\
Spring wheat & 18.6 & 206 & $3,592(394)$ \\
Rye & 7.5 & 81 & $2,378(399)$ \\
\hline
\end{tabular}

The indemnities of individual farms per year for each crop were aggregated, and fair premiums $F$ for each crop $c$ were derived. The total premium $T P_{c}$ for a crop $c$ is the sum of the fair premium $F_{c}$ and reserve loading $L_{c}$. In the literature, the event of an aggregate loss occurring that is so large that the collected insurance fund is exceeded is referred to as ruin (Bühlmann 1970). In order to minimize the probability of ruin in a given period or maximize returns subject to maintaining a specified probability of ruin, the insurance supplier collects a buffer fund $\mathrm{L}$ (Cummins 1991): 


$$
L_{c}=k \sigma \sqrt{N}
$$

where $k$ is specified from the chosen probability $1-1 / k^{2}$ that the insurance fund avoids ruin. Moreover, $\sigma$ is the standard deviation of the indemnity payments and $N$ is the size of the insurance pool. The insurance pool in this study was the cultivated hectares of a specific crop, because risk exposure and prices and thus fair premiums and reserve loadings differ between different crops. As the size of the insurance pool grows, the buffer fund amount allocated to each policy (reserve load per hectare) decreases.

\section{Stochastic simulation of farm-based insurance}

In this section, the stochastic simulation model for farm-based insurance is described. The simulation model used inputs from FADN and CDC data, which are described in the previous sections. CDC data were used to estimate the tail of the loss distribution, as extreme losses were not reflected in the FADN data set. Monte Carlo sampling was used as the sampling technique, in which random numbers are sampled from a priori specified distributions. Each of the obtained iterations represents a possible combination of values of the specified stochastic elements that could occur, taking into account correlations specified for the simulation model. The resulting values of output variables from iterations are computed and restored. Monte Carlo analysis in this study was based on 10,000 iterations. When the number of iterations is large enough, the distribution of each of the output variables will converge to a stable distribution (Hardaker et al. 2004). This distribution of output values reflects a realistic aspect of chance.

The overall indemnity $\mathrm{OI}$ of the crop insurance was calculated as the sum of the indemnities I for each crop $c$ in a given year:

$$
\mathrm{OI}=\sum_{\mathrm{c}=1}^{5} \mathrm{P}_{\mathrm{c}} \cdot \mathrm{I}_{\mathrm{c}} \cdot \mathrm{S}_{\mathrm{c}}
$$

The indemnities were estimated on the basis of the annual percentage of hectares experiencing a loss $P_{c^{\prime}}$ the average indemnity per crop $I_{c}$ and the average number of cultivated hectares $S_{c}$ of crop $c$ in the period 1995-2012 in Finland. For barley, oats, winter wheat, spring wheat and rye, respectively, the average number of cultivated hectares (S) in the period 1995-2012 was 543, 368, 25, 153 and 26 thousand hectares.

Average per-hectare indemnities and the number of cultivated hectares per crop were deterministic variables in the stochastic simulation model. The number of hectares lost per crop was a stochastic variable and used as an input in the simulation model of farm-based insurance. Five cumulative distributions of crop losses were constructed $(c=5)$ for the simulation model.

The cumulative probability distribution describes the probability that a random variable will be a value less than or equal to some value. In the farm-based insurance simulation model, the random variable $P$ was the annual percentage of hectares experiencing a loss. Cumulative probability distributions of the annual percentage of hectares experiencing a loss in farm-based insurance were obtained from the FADN data set. The $\mathrm{k}^{\text {th }}$ observation was used as an estimate of the $\mathrm{k} /(\mathrm{n}+1)$ fractile when the observations were arranged in ascending order (Hardaker et al. 2004). The range of the cumulative input curves was set by the observed minimum as well as the median values in the dataset. Maximum values were obtained from the two highest observations of the data in the farm-based insurance model. In FADN data there were only two years in which crop losses were considerably greater than the average losses (1998 and 1999). These years were used as separate data to estimate the scale of maximum losses in crop production. The mean and standard deviation of these two values were placed in a normal distribution. The $95^{\text {th }}$ percentile of the normal distribution defines the maximum value in the cumulative distribution. In this way, the maximum possible loss could be estimated by considering high losses as a separate distribution compared to normal yield variation. In addition, the $80^{\text {th }}$ percentile was added to the distribution functions to define the starting point for high losses.

Cumulative distribution functions (CDF) for the stochastic simulation model are displayed in Figure 1. The estimated maximum number of hectares lost per 1,000 cultivated hectares for oats, winter wheat, spring wheat, barley and rye was 306, 184, 544, 176 and 164 hectares, respectively. The respective median values in farm-based insurance CDFs were 61, 50, 26, 50 and 63.

Losses in the CDC scheme were estimated based solely on the past performance of the scheme, i.e. a stochastic simulation model was not used for the CDC data. In the CDC data, losses on field plots of individual farms are divided into total and partial losses. Total loss refers to the number of hectares for which the whole crop is destroyed. 
This includes $24 \%$ of the loss data. Information on losses on partially damaged sections of fields is incomplete ( $76 \%$ of cases). In our assessment, we therefore assumed that the loss in partially damaged hectares is $50 \%$ of the area reference yield. Farmers are eligible for full compensation when losses exceed the $30 \%$ deductible. The significance of the assumption that losses on partially damaged hectares amount to $50 \%$ of the area reference yield was examined with sensitivity analysis, where limits of $40 \%$ and $60 \%$ were studied. Correlation coefficients between crop losses were also derived for the CDC scheme.

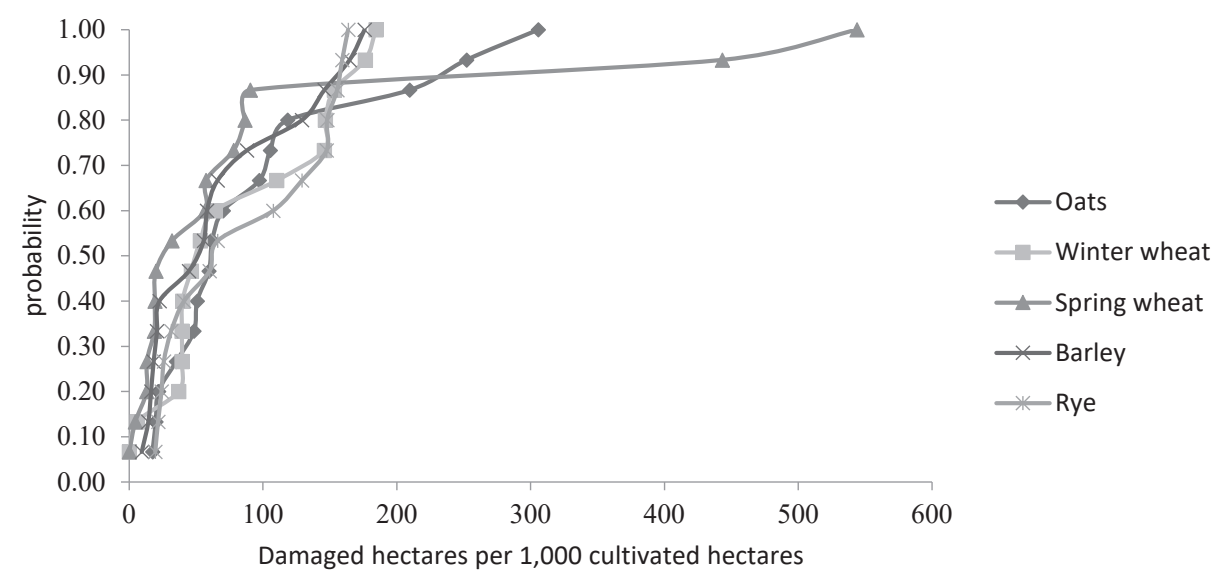

Fig. 1. Cumulative distribution functions of oats, winter wheat, spring wheat, barley and rye in the stochastic simulation model of farm-based insurance

Cereal crops do not significantly differ in their risk of exposure to adverse weather events. The stochastic nature of crop losses among different crops was taken into account in the stochastic simulation model. Stochastic dependencies between the crop-specific cumulative distributions were estimated using Pearson's correlation coefficient, and rank correlations were specified in the simulation models.

Bivariate rank correlations derived from the CDC and FADN data for the stochastic simulation model are displayed in Table 2. Correlations were used as inputs in the stochastic simulation model for farm-based insurance. The low correlation coefficients for the farm-based insurance scheme suggest that the number and spatial distribution of farms in the FADN dataset were not sufficient to give a good approximation of the systemic nature of crop losses in Finland. However, the CDC dataset includes a large number of farms that have experienced crop loss in Finland in recent years. Therefore, we can assume that the correlation of losses in the CDC scheme is a good approximation of the systemic nature of crop losses in Finland. Consequently, the farm-based insurance model was modelled with observed correlations from the FADN data and also with the correlations derived from the CDC data. All of the correlations of crop losses in the CDC scheme were found to be positive and significant. This reflects the rules of the CDC scheme, according to which the total yield of a farm must be below $30 \%$ of the reference yield before the farmer is eligible for compensation. Therefore, farmers collecting CDC payments are either seriously hit by adverse weather, when almost all their crops are damaged, or their farms are systematically producing under the reference yield level. In the farm insurance model, only losses to oats and barley were correlated at the $1 \%$ confidence level.

Table 2. Bivariate rank correlations for barley, oats, winter wheat, spring wheat and rye based on CDC and FADN data

\begin{tabular}{|c|c|c|c|c|c|c|c|c|}
\hline & \multicolumn{4}{|c|}{$\mathrm{CDC}$} & \multicolumn{4}{|c|}{ FARM INSURANCE } \\
\hline & Oats & Winter wheat & Spring wheat & Rye & Oats & Winter wheat & Spring wheat & Rye \\
\hline Barley & $0.95 * *$ & $0.74 * *$ & $0.90 * *$ & $0.82 * *$ & $0.96 * *$ & 0.26 & 0.42 & 0.31 \\
\hline Oats & & $0.71 * *$ & $0.88^{* *}$ & $0.83^{* *}$ & & 0.31 & 0.45 & 0.42 \\
\hline Winter wheat & & & $0.90 * *$ & $0.86 * *$ & & & 0.20 & 0.22 \\
\hline Spring wheat & & & & $0.93 * *$ & & & & -0.03 \\
\hline
\end{tabular}




\section{Results}

In this section, historical annual CDC payments are first presented. After this, the results from the farm insurance stochastic simulation model and insurance premiums are described. The final section of the results compares the distribution of losses and government expenditure on the CDC scheme and the simulated farm-based insurance.

\section{Government's risk exposure of the crop damage compensation scheme}

The annual CDC indemnity payments in Figure 2 illustrate that the total indemnity payments varied considerably during the period 1995-2012. The payments in Figure 2 are total realised indemnity payments under the CDC scheme (cereals + other crops). On average, the overall CDC payments totalled 5.91 million Euros per year. During 1995-2012, the average CDC payment per farm was 1,456 Euros. On average, 4,450 farms per year received payments during that period. The share of farms receiving crop damage compensation payments in Finland varied during the study period from $29.5 \%$ in 1998 to $0.7 \%$ in 2009.

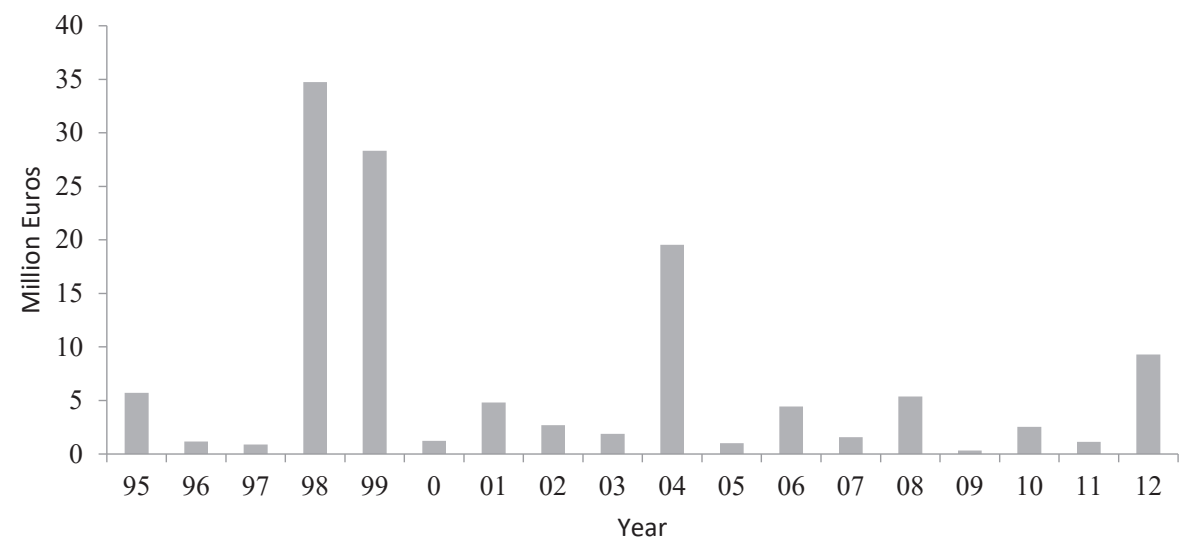

Fig. 2. Total indemnity payments under the crop damage compensation scheme in 1995-2012 (millions of Euros)

Table 3. Average number of hectares lost (total and partial loss hectares per 1,000 cultivated hectares) and indemnity payments per year for barley, oats, winter and spring wheat and rye in the CDC scheme (1995-2012)

\begin{tabular}{lllll}
\hline & Average hectares lost $(\mathrm{SD})^{1}$ & $\begin{array}{l}\text { Total losses } \\
\%\end{array}$ & $\begin{array}{l}\text { Partial losses } \\
\%\end{array}$ & $\begin{array}{l}\text { Average indemnity payment Euros/ } \\
\text { hectare }(\text { spread })^{2}\end{array}$ \\
\hline Barley & $23.21(59.07)$ & 19 & 81 & $136.9(106.3-167.8)$ \\
Oats & $23.17(54.61)$ & 39 & 61 & $158.2(133.8-186.0)$ \\
Winter wheat & $33.95(98.49)$ & 14 & 86 & $116.8(75.8-157.7)$ \\
Spring wheat & $49.22(135.96)$ & 16 & 84 & $143.9(103.0-184.9)$ \\
Rye & $28.18(69.86)$ & 59 & 41 & $118.1(92.1-144.2)$ \\
\hline
\end{tabular}

${ }^{1}$ Average hectares lost $=$ (hectares with total loss + hectares with partial loss)/cultivated area

${ }^{2}$ Average indemnity payment in Euros: losses equivalent to $50 \%$ of the area reference yield. Lower limit: losses equivalent to $60 \%$ of the area reference yield. Upper limit: losses equivalent to $40 \%$ of the area reference yield.

The overall number of hectares of cereal crops lost in the CDC scheme varied significantly between years. The largest number of hectares experiencing a loss was in 1998, when 323,000 cereal hectares were eligible for CDC payments. This represents some $28 \%$ of the total cultivated area of these crops in 1998. Table 3 describes the average number of hectares lost per 1,000 cultivated hectares for each crop in the CDC scheme. The average loss and standard deviation of losses was highest for spring wheat and lowest for oats. The average indemnity payment (Euros/hectare) was highest for oats (158.2 Euros/hectare) and lowest for winter wheat (116.8 Euros/hectare).

\section{Risk exposure of insurance companies and fair premiums for the farm-based insurance scheme}

The average number of hectares lost derived from the FADN data was on average higher than in the CDC scheme. This is due to the different methods for defining reference yields in the two schemes. The variability in annual hectares lost was lower in the farm-based insurance than in the CDC scheme. However, the standard deviation of losses between years was considerable in farm-based insurance. Indemnity payments for barley, oats, winter and spring wheat and rye totalled 50.2, 48.2, 72.5, 57.3 and 50.1 Euros/hectare, respectively. 
The probability of losses under the farm-based insurance scheme is distributed into layers in Table 4. The probability that indemnity payments from the farm insurance scheme will be $0-5$ million Euros is $64 \%$. The probability that payments will exceed 5 million Euros, but will be less than 10 million Euros, is $28 \%$. Therefore, the probability that indemnity payments will exceed 10 million Euros is only $8 \%$. When crop losses are highly correlated, i.e. correlation coefficients from the CDC scheme are used, these probabilities are $67 \%, 22 \%$ and $11 \%$, respectively. Based on the simulation model, the maximum amount of indemnity payments per year will be 15-16 million Euros. Maximum possible losses from the farm-based insurance scheme are much lower than in the CDC scheme (Fig. 2).

Table 4. Annual indemnity payments from farm-based insurance subdivided into layers (in parentheses, results if loss correlations from the CDC scheme are used)

\begin{tabular}{llll}
\hline $\begin{array}{l}\text { Crop losses } \\
\text { (million Euros) }\end{array}$ & Probability & $\begin{array}{l}\text { Expected value } \\
\text { (million Euros) }\end{array}$ & $\begin{array}{l}\text { Spread } \\
\text { (million Euros) }\end{array}$ \\
\hline $0-5$ & $0.64(0.67)$ & $2.5(2.3)$ & $0-5(0-5)$ \\
$5-10$ & $0.28(0.22)$ & $7.1(7.0)$ & $0-10(0-10)$ \\
$>10$ & $0.08(0.11)$ & $11.8(12.7)$ & $0-15(0-16)$ \\
\hline
\end{tabular}

Crop losses are systemic in nature, and indemnity payments vary considerably between years. Moreover, indemnity payments vary considerably between farms within a single year. Therefore, insurance companies need to take varying losses into account when crop insurance products are developed and priced. Moreover, a reserve loading needs to be added to insurance premiums (Skees and Barnett 1999). For the farm-based insurance scheme, the reserve loading per hectare for each crop was defined as in equation 3 and divided by the average number of cultivated hectares in the FADN dataset.

The simulated fair premium for barley, oats, winter wheat, spring wheat and rye was 3.6, 4.3, 5.3, 5.0 and 4.2 Euros/hectare, respectively. These amounts are on average $8 \%$ of the average indemnity payment per hectare. If the premium subsidy covers $65 \%$ of premiums, the premium as a proportion of the expected compensation is some $3 \%$. The simulated fair premiums do not represent a major change if crop losses are highly correlated. The percentage share of average reserve loadings from fair premiums is $5.2 \%, 4.2 \%, 40.1 \%, 14.8 \%$ and $27.6 \%$, respectively, when the probability of ruin is $5 \%$. The probability of ruin reflects the probability that aggregated yearly indemnities exceed the collected premiums. The $5 \%$ probability for ruin means that such an event occurs once in 20 years. Thus, it can be seen as normal variation in yields, and losses exceeding this limit should be covered by catastrophic loading.

\section{Comparison of the CDC and farm-based insurance schemes}

Mean loss hectares per year were estimated to be higher in the farm-based insurance than in the CDC scheme (Table 5). In the CDC scheme, losses are more skewed to the right than in the farm-based insurance scheme. Moreover, the standard deviation and maximum losses for barley, winter wheat and rye are higher in the CDC scheme. According to Myyrä and Jauhiainen (2012), the CDC scheme was considerably affected by moral hazard. Some farms received payments from the CDC scheme very frequently, and there were no incentives for farmers to avoid yield losses if they experienced crop damage. This can also be detected from the longer tail (loss distributions are more skewed to the right) of the CDC loss distributions compared to farm-based insurance.

Table 5. Distribution of historical annual hectares lost (total and partial lost hectares per 1000 cultivated ha) in the CDC scheme and estimated annual hectares lost (hectares where losses exceed the $30 \%$ deductible level per 1000 cultivated ha) under the farm-based insurance scheme

\begin{tabular}{llllllll}
\hline & \multicolumn{3}{c}{ CDC scheme } & \multicolumn{3}{c}{ Farm-based insurance } \\
\hline & Mean (SD) & Skewness & Maximum value & & Mean (SD) & Skewness & Maximum value \\
\cline { 2 - 4 } Barley & $23.21(59.07)$ & 3.3684 & 240.15 & & $71.47(50.30)$ & 0.6068 & 175.85 \\
Oats & $23.17(54.61)$ & 2.6436 & 185.66 & $90.21(71.60)$ & 1.3908 & 305.69 \\
Winter wheat & $33.95(98.49)$ & 3.2536 & 386.03 & $73.44(58.17)$ & 0.5346 & 184.39 \\
Spring wheat & $49.22(135.96)$ & 3.3706 & 545.72 & $86.59(131.76)$ & 2.0501 & 543.43 \\
Rye & $28.18(69.86)$ & 2.9747 & 264.20 & $83.42(48.52)$ & 0.3929 & 163.56 \\
\hline
\end{tabular}

The comparison of the CDC scheme and farm-based insurance scheme reveals that higher mean losses are expected under farm-based insurance. This may result in a bias where insurance companies underestimate the overall risk exposure of crop production at the farm level. If farmers are aware of the true yield risks they are facing, this may lead to losses for insurance companies. On the other hand, if farmers are not aware of the true risks they are 
facing, which insurance companies have a good understanding of, the demand for crop insurances may be too low, as farmers' willingness to pay for crop insurance may be too low from point of view of insurance companies.

Insurance companies are concerned about the expenses related to estimates of crop damage compensation payments. These are next presented for the CDC scheme and farm-based insurance. The estimated average and median expenditure per year are presented in Table 6 . The maximum rate of premium subsidy can be $65 \%$ of the crop insurance premium (EU 2013). This percentage was used in expenditure calculations for farm-based insurance. The simulated farm-based insurance scheme is funded by the government (65\% of premiums) and farmers (35\% of premiums), while the CDC scheme was fully financed by the Finnish government. The mean government expenditure is expected to be lower in the future due to the policy shift in Finland. The mean costs from farm-based insurance would be 4.9 million Euros per year (without administrative costs). In the CDC scheme, the estimated government costs for barley, oats, winter and spring wheat and rye were on average some 5.6 million Euros per year in total.

Table 6. Mean and median costs of the farm-based insurance and CDC schemes

\begin{tabular}{llll}
\hline & Mean million Euros (SD) & $\begin{array}{l}\text { Median million Euros } \\
\text { (0.05th fractile-0.95th fractile) }\end{array}$ \\
\hline CDC & & $5.6(8.3)$ & $1.3(0.4-22.8)$ \\
Farm-based insurance & Government & 3.2 & $2.1(0.7-8.9)$ \\
& Farmers & 1.7 & $1.1(0.4-4.8)$ \\
\hline
\end{tabular}

From the simulation model, we can also estimate the average expenditures per year for the government from a 'stop-loss' contract designed for the farm-based insurance scheme. In the simulated 'stop-loss' contract, the government covers losses if indemnity payments exceed some predefined threshold. For example, the probability that indemnity payments exceed this in one year is 0.11 if the threshold is set at 10 million Euros. Moreover, the corresponding average 'stop-loss' expenditure is 2.7 million Euros. Thus, the price of a 'stop-loss' policy with a threshold of 10 million Euros for the government is 0.3 million Euros $(0.11 \times 2.7)$. If the 'stop-loss' contract threshold is set to 12 million Euros, the probability for government payments per year is 0.07 . Moreover, the average expenditure per year is 1.7 million Euros and the price of the 'stop-loss' policy for the government would be 0.1 million Euros.

\section{Discussion and conclusions}

Finland is at the northern limit of agriculture, where the harsh climate and unpredictable weather conditions increase the risks in crop production. The government-funded crop damage compensation (CDC) scheme was designed to cover crop losses in Finland. However, it has been abolished. EU member states were able to use CAP subsidies for crop insurance schemes in 2015, but this possibility was not utilised in Finland. In this study, we addressed the question of how government expenditure would change due the policy shift from a system fully financed by the government to an insurance scheme based on PPP. The risk exposure of crop insurance based on individual farm yields was compared with that of the CDC scheme.

Our research provides insight for governments in the northern hemisphere into the implications of changing from a public risk management scheme to a system involving public-private partnership and farm-based insurance. The policy switch to a public-private scheme appears beneficial for multiple reasons, including the lower average and smaller variation in budgetary expenditure for the Finnish government and increased incentives for good farming practices due to improved possibilities for risk sharing. The insurance scheme also maintains incentives for risk prevention due to the retention level. The maximum possible losses from the farm-based insurance scheme are also expected to be much lower than in the CDC scheme. However, the lack of knowledge of these advantages for the government may delay the actual implementation of the partnership. Thus, there is a clear demand for the results obtained with the current research.

The results obtained support the government's decision to terminate the CDC scheme. The results also form an important basis for the further development of private insurance schemes. The high variability in government expenditure will diminish, and in the future, farmers purchasing crop insurance will bear a larger share of the yield risks than under the CDC scheme. If the government decides to provide a 'stop-loss' contract for insurance companies, the cost of this policy will on average be 0.3 million Euros per year if the threshold of the 'stop-loss' policy is set to 10 million Euros. 
A 'stop-loss' contract should be in use for the first operational years to make crop insurance markets more attractive to insurance companies. Hardaker et al. (2004) pointed out that if the government guarantees the viability of insurance markets on a regular basis, the insurer will have little incentive to use sound insurance practices when calculating premiums and assessing losses. While markets are just emerging, such 'stop-loss' measures may be needed to build up interest among insurance companies. However, it is worthwhile pointing out that such a 'stop-loss' contract is not currently possible under Finnish legislation.

In preparing for large losses, insurance companies can collect buffer funds. Our results indicate that when the probability of ruin is as low as $5 \%$, the reserve loading should be $4-28 \%$ of the fair premium, depending on the cereal crop. The rest of the risks, as these are now clearly bounded, can be reinsured. Through these procedures, insurance companies can have a good understanding of the risks and liabilities related to yield insurances.

These results are the first estimates for the government expenditure and loading needed for yield insurance in Finland. However, the estimated reserve loading of $4-28 \%$ of the fair premium is only a part of the true loading needed to operate viable insurance schemes. Loading will be extended by the administrative costs and taxes to be covered. However, the results presented in this paper give some justified boundaries for the discussion.

Our results suggest that insurance schemes based on PPP and individual farm yields are preferred to a governmentrun programme with an area-based indemnity payment trigger. Therefore, we encourage countries to develop agricultural risk management schemes that are based on PPP instead of relying on government-run programmes or disaster relief. The main advantage is that government expenditure is expected to be less variable under public-private insurance schemes. Moreover, farm-based insurance schemes are better in dealing with asymmetric information issues. However, the adverse selection problem arises for insurance companies if more risky farmers are the first to purchase yield insurance products. Thus, the insurance companies need to identify risk profiles to collect higher premiums from more risky farmers rather than collecting average fair premiums, as was assumed in this research. In this study, we only considered the fair premiums for a crop insurance scheme. However, Ker (2001) found that the delivery costs of crop insurance programmes in the US are excessive, which should be taken into account when considering PPP crop insurance schemes in the EU. In addition, the costs and feasibility of different risk management schemes, e.g. index and revenue insurances, should be studied in the future.

\section{References}

Bühlmann, H. 1970. Mathematical methods in risk theory. New York: Springer-Verlag. 210 p.

Cummins, D.J. 1991. Statistical and financial models of insurance pricing and the insurance firm. The Journal of Risk and Insurance 58: 261-302. https://doi.org/10.2307/253237

EU 2013. Regulation (EU) No 1305/2013 of the European Parliament and of the Council of 17 December 2013 on support for rural development by the European Agricultural Fund for Rural Development (EAFRD) and repealing Council Regulation (EC) No 1698/2005. http://eur-lex.europa.eu/LexUriServ/LexUriServ.do?uri=OJ:L:2013:347:0487:0548:EN:PDF. Accessed 18 February 2014.

Goodwin, B.K. \& Vado, L.A. 2007. Public responses to agricultural disasters: Rethinking the role of government. Canadian Journal of Agricultural Economics 55: 399-417. https://doi.org/10.1111/j.1744-7976.2007.00099.x

Hardaker, J.B., Huirne, R.B.M., Anderson, J.R. \& Lien, G. 2004. Coping with risk in agriculture. Cambridge. CABI Publishing. 352 p. https://doi.org/10.1079/9780851998312.0000

Ker, A.P. 2001. Private insurance company involvement in the U.S. crop insurance program. Canadian Journal of Agricultural Economics 49: 557-566. https://doi.org/10.1111/j.1744-7976.2001.tb00326.x

Mangen, M.-J.J., Nielen, M. \& Burrell, A.M. 2002. Simulated effect of pig-population density on epidemic size and choice of control strategy for classical swine fever epidemics in The Netherlands. Preventive Veterinary Medicine 56: 141-163. https://doi. org/10.1016/S0167-5877(02)00155-1

Meuwissen, M.P.M, Assefa, T.T. \& van Asseldonk, M.A.P.M. 2013. Supporting insurance in European agriculture: Experience of mutuals in the Netherlands. EuroChoices 12: 10-16. https://doi.org/10.1111/1746-692X.12034

Meuwissen, M.P.M., van Asseldonk, M.A.P.M. \& Huirne, R.B.M. 2003. Alternative risk financing instruments for swine epidemics. Agricultural Systems 76: 305-322. https://doi.org/10.1016/S0308-521X(02)00072-0

Meuwissen, M.P.M., Hardaker, J.B. Huirne, R.B.M. \& Dijkhuizen, A.A. 2001. Sharing risks in agriculture: Principles and empirical results. NJAS Wageningen Journal of Life Sciences 49: 305-356. https://doi.org/10.1016/S1573-5214(01)80022-1

Mintiens, K., Laevens, H., Dewulf, J., Boelart, F., Verloo, D. \& Koenen, F. 2003. Risk analysis of the spread of classical swine fever virus through 'neighbourhood infections' for different regions in Belgium. Preventive Veterinary Medicine 60: 27-36. https://doi. org/10.1016/S0167-5877(03)00080-1

MT 2013. Maatilojen ja metsien vakuuttaminen kallistuu. Maaseudun tulevaisuus 2.9.2013.

Myyrä, S. \& Jauhiainen, L. 2012. Farm-level crop yield distribution estimated from country-level crop damage. Food economics 9: $157-165$. 
Myyrä, S. \& Pietola, K. 2011. Testing for moral hazard and ranking farms by their inclination to collect crop damage compensations. In: European Association of Agricultural Economists. 2011 International Congress. Zurich.

Niemi, J.K., Lehtonen, H., Pietola, K., Lyytikäinen, T. \& Raulo, S. 2008. Simulated financial losses of classical swine fever epidemics in the Finnish pig production sector. Preventive Veterinary Medicine 84: 194-212. https://doi.org/10.1016/j.prevetmed.2007.12.006

Skees, J.R. \& Barnett, B.J. 1999. Conceptual and practical considerations for sharing catastrophic/systemic risks. Review of Agricultural Economics 21: 424-441. https://doi.org/10.2307/1349889

Smith, V.H. \& Glauber, J.W. 2012. Agricultural insurance in developed countries: Where have we been and where are we going? Applied Economic Pespectives and Policy 34: 363-390. https://doi.org/10.1093/aepp/pps029

van Asseldonk, M.A.P.M., Meuwissen, M.P.M. \& Huirne, R.B.M. 2001. Stochastic simulation of catastrophic hail and windstorm indemnities in the Dutch greenhouse sector. Risk Analysis 21: 761-769. https://doi.org/10.1111/0272-4332.214148

WTO 1994. Agreement on agriculture, GATT, Marrakesh Agreement 1994, World Trade Organization. Geneva. https://www.wto. org/english/docs_e/legal_e/14-ag_01_e.htm 